\title{
ON
}

\section{EXCESS OF UREA IN THE URINE}

AS A GUIDE TO THE

DIAGNOSIS AND TREATMENT OF CERTAIN FORMS OF DYSPEPSIA AND NERVOUSNESS.

BY

HENRY WILLIAM FULLER, M.D. Cantab., F.R.C.P.L., PHYSIOIAN TO ST. GRORGK's HOSPITAL.

Received Oct. 3rd.-Read November 26th, 1867.

In the year 1864. I had occasion to examine the urine of a patient who was suffering from symptoms of a nervous and dyspeptic character. The urine was frothy, somewhat pale and clear, sp. gr. 1025 ; it had an acid reaction and a strong urinous smell; it contained neither sugar nor albumen, and only a few small crystals of oxalate of lime were visible under the microscope, but the addition of nitric acid caused intense effervescence, and about twenty minutes after this had subsided crystals of nitrate of urea began to form and ultimately filled the interior of the test-tube. During a period of rather more than three weeks I examined this' patient's urine every second day, and invariably found it to contain urea in quantity sufficient to crystallize readily on the addition of nitric acid, without any previous evaporation or concentration of 
the urine. The degree of crystallization varied at each examination, in consequence, doubtless, of a variation in the amount of the urea contained in a given bulk of the urine; but inasmuch as I could not persuade the patient to save and measure the quantity of urine voided in twenty-four hours, I am unable to state whether less urea was secreted when the crystallization was at its minimum, or whether the variation arose from an increase in the quantity of water and a consequent dilution of the urea. The patient, however, declared, as the result of his observation, that he was passing about two pints of urine, and that the quantity scarcely varied from day to day.

The patient was thirty-seven years of age, of spare habit, in good condition, and apparently healthy; he was not a large eater, but he relished his food, and ate meat three times a day. His principal complaint was of nervousuess and depression of spirits, indisposition for exertion, whether mental or bodily, and dyspepsia, with irregularity of the bowels, acidity of stomach, and excessive flatus.

The case made a strong impression on me at the time, for the reason that I was not prepared for the discovery of so much urea, and had never heard such cases spoken of by my professional friends or seen any notice of them by authors. I have therefore kept the matter steadily in view, and within the last two years have examined the urine of every patient in whom, judging from the character of the symptoms, I have thought it likely that urea might exist in excess. ${ }^{1}$ The result has been that $I$ have detected urea in

1 By excess of urea in the urine I mean simply to imply that there is an excess of urea in a given bulk of the urine-an excess sufficient to lead to its crystallization on the addition of nitric acid without any previous concentration of the urine. In some of the instances referred to it was ascertained by actual analysis that the quantity of urea excreted in twenty-four hours was decidedly above the average, and I believe that it was so in every instance; but inasmuch as considerably difficulty is experienced in private practice in obtaining the whole quantity of urine voided in twenty-four hours, the amount of urea excreted in that period has been determined only in six cases, and I am therefore unable to speak positively as to the fact, in the other instances. 
excess in twenty-seven cases, and so well marked and peculiar are the symptoms by which that condition of the urine is accompanied, that now, if the features of the patient's malady induce me to suspect its existence and to examine the urine with a view to its discovery, I am seldom disappointed in obtaining the characteristic crystals of nitrate of urea.

The cases under discussion resemble each other so closely in many of their more prominent symptoms, that it will suffice to give the details of one or two which may be fairly taken as samples of the whole.

A. T-, æt. 43 , a spare but healthy looking man, 5 feet 8 inches in height, 10 stones $9 \mathrm{lbs}$. in weight, of florid complexion, but somewhat bilious temperament, reported that he had been nervous throughout his life, and since the age of thirty had not felt well for any lengthened period. If he had unusual worry in his profession or any anxiety in his family, or even if he was unable to obtain his ordinary amount of outdoor exercise, he was apt to become irritable, low, and depressed, indisposed for exertion, and easily fatigued, unable to fix his mind on any subject requiring continuous application, and afraid to encounter the rubs and vexations incident to his daily life. His present illness he attributed to anxiety arising from the illness of one of his children, together with the want of his usual exercise. $\mathrm{He}$ had been remarkably well for some time previously, and became conscious of some change or disturbance in his system within a week after the commencement of his trouble. At first he became restless at night; then drowsy after meals, especially after dinner, and began to suffer from flatulence and acidity; shortly he found himself nervous and dejected without obvious cause, especially in the morning, unable to apply himself to his professional duties, and unwilling, if not unequal, to take his wonted exercise. Nervous fancies and wretched feelings, occasional giddiness, fugitive pains in various parts of the body, and a sense of extreme languor and weariness, rendered his life miserable. For six weeks before he consulted me he 
had been taking a series of Turkish baths, and had dieted himself carefully, but notwithstanding his care the dyspeptic symptoms had continued, and his mental disquietude was more constant than before.

When I first saw him he was restless at night, but obtained a fair amount of unrefreshing sleep; his skin was rather dry, but perspired readily after exercise; his pulse ranged from 84 to 96 ; his appetite was tolerable, but not so good as usual; he ate meat twice a day, and was in the habit of drinking four or five glasses of sherry or an equivalent amount of claret, but he never drank beer; after each meal he suffered greatly from flatulence and drowsiness, and after breakfast experienced a sense of uneasiness about the head and of heat and weariness of the eyes. His bowels were somewhat torpid, but usually acted without the aid of medicine; his urine he said was " all right," and with the exception that it was frothy or strongly beaded it certainly did not present an unhealthy appearance. Occasionally it threw down a deposit of the lithates, but more commonly it was clear, pale, acid, of a strong urinous odour, sp. gr. 1026, and was free from sugar and albumen. Under the microscope a few octohedral crystals of oxalate of lime and here and there a few epithelial cells were visible, but they were scarcely more numerous than in healthy urine. On the addition of nitric acid to the extent of about one third of the bulk of the urine a strong effervescence took place, and within twenty minutes after this had subsided crystals of nitrate of urea had formed to such an extent that the whole of the urine in the test-tube appeared to be converted into a solid mass. On some occasions the crystals of nitrate of urea did not occupy above half the bulk of the urine, but commonly they filled two thirds of the space occupied by the urine. My friend Dr. Dickinson, who kindly examined a sample taken from the entire quantity of the urine (1927 c.c.) voided in twenty-four hours, reported that the day's excretion contained 53.9 grammes of urea, or nearly 21 grammes in excess of the average amount excreted within that period according to the observations of Dr. Parkes. 
The next and only other case which I shall detail is of a very similar character. The patient, a gentleman closely engaged in the city, was 37 years of age, about 5 feet 7 inches in height, and 10 stones 2 lbs. in weight, of sallow complexion, but healthy aspect. He said that he had enjoyed excellent health until the age of 29 , when he had a severe attack of fever, which left him in shattered health and extremely nervous. Some months elapsed before he regained his strength and was able to resume business, and he had suffered ever since, on slight occasions, from disturbance of the digestive organs, as evidenced by flatulence after meals, palpitation, colicky pain in the abdomen, and a tendency to acidity and diarrhœa. Accompanying these symptoms there was a distressing sense of depression, a disinclination to exertion, and an inability to apply himself steadily to work. He was always fearing some impending calamity, some serious and irremediable bodily affliction, or some loss or misadventure in business. His skin was cool and rather inactive; pulse 84 . Tongue coated; bowels at one time costive, at another relaxed. The urine was frothy or firmly beaded, clear, acid, of pale sherry colour, sp. gr. 1028. It had a strong urinous smell, and was perfectly free from sugar and albumen. Nothing noteworthy was observed under the microscope; on the addition of nitric acid an intense effervescence ensued, and within half an hour crystals of nitrate of urea began to form and soon filled two thirds of that portion of the tube occupied by the urine. In this case, as in the last, Dr. Dickinson kindly determined the amount of urea excreted in twenty-four hours by examining a sample taken from the entire quantity of urine (1359 c.c.) which had been passed, and he found that it amounted to $55 \cdot 1$ grammes, or $22 \cdot 1$ grammes in excess of the average. In four other cases, in which, at my request, Dr. Dickinson determined the quantity excreted in twenty-four hours, it was found to amount to 42.5 grammes, 41.8 grammes, 39.06 grammes, and 51 grammes.

Now, all the instances which have come under my notice have had several features in common. With one exception, vol. LI. 
that of a lady, aged forty-three, the patients have all been males, varying in age from twenty-three to fifty-four. Most of them have been essentially meat eaters, partaking sparingly of bread and other varieties of farinaceous food, but five of them ate meat only twice daily, and one, a member of our own profession, declared, not only that he never touched meat except at dinner, but that even then the principal part of his meal consisted of vegetable and farinaceous food. Without exception, the patients have been tolerably healthy in appearance, and often somewhat florid, though in some instances they have lost flesh slightly; indeed, their aspect has been so little indicative of disease, and their complaint of suffering has been so urgent, that any practitioner who did not examine the urine for urea would have surely regarded them as simply hypochondriacal. Usually the pulse has been quick and rather weak, and the patients' complaint has been of languor, flatulence, restlessness at night, and extreme nervousness. They have been afraid of encountering the rubs of everyday life, and in some instances have for the time lost their pleasure in society; they have eaten fairly, though with less than their usual relish, and the feeling of languor which has oppressed them, and of fatigue which has followed even a moderate amount of exertion, has led to their abstaining almost wholly from exercise. They have usually complained of extreme depression in the morning, with a sense of heat about the eyes, muzziness in the head, and weariness after breakfast-feelings which have in some measure passed off as the day has advanced, and they have partaken, as usual, of stimulants. The condition of the urine has varied; at one time it has been scanty, and loaded with lithates; at another abundant, or even excessive in quantity, of a light sherry colour and strong urinous odour; and these alternations have been repeatedly observed in the same case at intervals of a few days, or even of a few hours. The pale and clear urine, of a specific gravity varying from 1029 to 1032 , and quantity from $32 \mathrm{oz}$. to $64 \mathrm{oz}$., is that which has usually contained the largest quantity of urea, and it has remained markedly frothy or beaded for twenty- 
four or thirty-six hours, just like diabetic or highly albuminous urine. Dr. Prout has stated ${ }^{1}$ that " urine containing a large proportion of urea is prone to decomposition, and generally soon becomes alkaline ;" but in the cases under consideration the urine, even when exposed to the air, will remain acid and free from decomposition for two or three weeks in warm weather, and in cold weather will remain unchanged for as many months.

The method I have adopted in testing the urine has been to add to a small quantity of it in a test-tube about one third of its bulk of nitric acid, and then to shake the tube until all effervescence has subsided. The tube is then left at rest, to allow of crystallization of nitrate of urea to take place. In cold weather this is commonly effected in twenty minutes or half an hour, and it will usually occur in about the same time even in hot weather if the test-tube is immersed in a bath of cold water.

It should, perhaps, be added that the tendency to a recurrence of this form of disease is very great, and several of the patients have consulted me in reference to the same train of symptoms on more than one occasion.

The treatment adopted has varied in its details, but that which has proved most successful is based upon the view which I take of the pathology of the disease, namely, that it is connected primarily with perverted nervous action, in consequence of disturbed assimilation. Neurine tonics, such as arsenic, quinine, strychnia, iron and zinc, together with the mineral acids, the shower bath, and the dripping sheet, are the remedies which have proved most successful in my hands, and when combined with alterative doses of blue pill and colchicum will usually afford relief. In one or two instances, characterised by extreme irritability, the bromide of potassium, in conjunction with iron, has proved a more effective remedy, and occasionally the hypophosphite of soda has been serviceable.

The form of disease which I have thus endeavoured to bring before the Society has not as yet received distinct 1 'On the Stomach and Urinary Diseases,', 3rd edit., p. 94. 
recognition, though the peculiarity of the symptoms by which it is signalised are such, I think, as entitle it to be regarded as a special form of derangement. Except in Dr. Prout's classical work on 'Stomach and Urinary Diseases,' I find no mention made of it in any treatise on the urine published in this country. Even Dr. Prout regards it as very rare, and, while suggesting its close connection with diabetes mellitus, declares (p. 96) that "where he has seen one case of an excess of urea in adults, he has seen twenty cases of diabetes." Dr. Parkes, referring to Dr. Prout's observations on these cases of azoturia, distinctly states, " "I have never seen a disease of this kind." It is obvious, therefore, not only that this condition of the urine has, in many instances, escaped recognition, but that the form of derangement on which it depends requires careful investigation.

The symptoms by which it is characterised appear to me to necessitate a complete revision of the theory hitherto accepted respecting the cause of the presence of urea in the urine. Up to the present time it has been held that urea is formed principally, if not solely, during the destructive processes of assimilation as a result of oxidation of the tissues, and in confirmation of this opinion most authors have asserted that it is found in largest quantities after violent exercise and during the excitement of febrile disorders, when the waste of tissue is at its maximum.2 But $I$ altogether doubt this statement, and certainly in the class of cases now brought before the Society this condition of affairs is reversed. The patients ordinarily remain in fair bodily condition, lose very little flesh, and bear the aspect of health; they are languid and lethargic while the attack is present, and take little exercise; their appetite is good, though their zest for food is impaired; and their principal complaint is of dyspepsia, prostration, and nervous derangement, so that they are often regarded as simply nervous and hypochondriacal. In short, it would appear that the azoturia must have some

\footnotetext{
1 'On the Urine,' p. 374.

2 See Parkes, Beale, Hassall.
} 
other source than the wear and tear of the tissues, and there are only two probable explanations of its occurrence-the one that it is referable, in part at least, to the production of urea from the elements of the food during the primary processes of assimilation, as a consequence of perverted nervous action; the other that a larger quantity than usual of the nitrogenous elements are secreted by the kidneys in consequence of a defective secretion of nitrogenous matters by the bowel. The recent experiments recorded by Dr. Parkes $^{1}$ would seem to show that this latter is at least a possible explanation, and unless, in any given case, the urine and the excreta from the bowels could both be examined, it cannot be affirmed positively that it does not afford a solution of the mystery. But it appears far more feasible to suppose that a certain portion of the food, instead of being utilised in the system, undergoes conversion into urea, and is then excreted without having fulfilled its mission in the animal economy. In the class of cases under consideration, the bowels are not more than ordinarily torpid, nor is there any evidence of defective intestinal secretion, whereas there are marked symptoms throughout of disturbed digestion and of perverted nervous action.

Several circumstances lead me to believe that this affection is more nearly allied to gout than it is to diabetes, as suggested by Dr. Prout. In the first place, not a trace of sugar was detected in the urine in any instance, though it was invariably sought for. Secondly, no less than eleven out of the twenty-seven patients were the offspring of gouty parents, and three of them had actually suffered from gout. Thirdly, the urine was often highly charged with lithates, and occasionally threw down crystals of uric acid, indicating a strong tendency to the lithic acid diathesis. Fourthly, in most instances the quantity of urea appeared to vary inversely as the quantity of uric acid. I speak hesitatingly on this point, because, unfortunately, the amount of uric acid in each specimen of urine was not determined by analysis ; but when the urine proved, as it usually did, clear and often pale at

${ }^{1}$ See 'Med. Times and Gazette,' April 13th, 1867. 
one time, and high coloured and loaded with lithates at another, the urea was invariably found to exist in largest quantities, as shown by the crystallization of nitrate of urea in those specimens of urine which were free from lithates, although the quantity of urine voided on those occasions was larger than when the lithates were deposited. If, on further examination, a direct relationship should prove to exist between the quantity of urea and uric acid excreted in these cases, another link would be added to the chain of events which appear to exercise a bearing on the causation of gout. At present my information on the subject is too imperfect to warrant such a conclusion, but $I$ have deemed it expedient to draw attention to the facts as far as I have hitherto ascertained them.

In conclusion, I would express my regret that the difficulties which are encountered in private practice in inducing patients to preserve the whole of the excreta from the kidneys and bowels have prevented my ascertaining, by actual analysis, the cause of the excessive quantity of urea in the urine. Hospital practice, in which precise observations can alone be carried out with certainty and regularity, furnishes comparatively few of the class of cases under discussion, one only out of the twenty-seven cases having occurred amongst my patients at St. George's Hospital. But now that attention has been drawn to the subject, it probably will not be long before some gentleman has the opportunity of supplying what I feel to be a deficiency in this communication.

\section{Appendix, July 7th, 1868.}

Since the above paper was communicated to the Society, I have had the opportunity of verifying my observations in thirty-three additional instances, in four of which the subjects were females. These cases have not thrown any additional light on the nature of the disorder, but they have served to confirm the opinion I have propounded as to its origin, and also to show that this form of malady is essentially distinct 
from that variety of azoturia which is accompanied by rapid wasting, of which Dr. Sydney Ringer's case affords a notable example.

I would also add that my attention has been drawn to the fact that Dr. Handfield Jones published some pertinent remarks on azoturia in a paper which appeared in the 'British Medical Journal' for October 12th, 1861, and that he afterwards enlarged upon them in his work on 'Functional Nerve Disorder,' pp. 438-441. Dr. Sieveking also discussed the subject in the 'British Medical Journal' for June 3rd, 1865, suggesting that the disorder described by Dr. Golding Bird as oxaluria was in truth azoturia, the malady now under consideration. 